\title{
Empirical modelling of temperature in fogging greenhouse
}

\author{
Khachonsak Simek ${ }^{1 *}$, Krawee Treeamnuk ${ }^{2}$, and Tawarat Treeamnuk ${ }^{2}$ \\ ${ }^{1}$ Suranaree University of Technology, Institute of Engineering, School of Mechanical Engineering, \\ 30000, Thailand \\ ${ }^{2}$ Suranaree University of Technology, Institute of Engineering, School of Agricultural Engineering, \\ 30000 , Thailand
}

\begin{abstract}
The objective of this article is to evaluate the inside temperature of greenhouse and efficiency of fogging system under the influence of solar power. A $50 \%$ off sun shading roof was selected to test in this study. Testing is divided to 2 cases. Case I Measuring all of parameters without operate the fogging system and ventilation between 9.00 a.m. to 5.00 p.m. (Thailand's time zone). Case II Measuring all of parameters with a fogging system that was controlled the relative humidity below $80 \%$ all day. The results show that the highest temperature in greenhouse is $50.13^{\circ} \mathrm{C}$ (no fogging and ventilation). the developed empirical model has an error $6.33 \%$ between numerical results and measured air temperature. In case of neglected solar power, the model showed that the fogging system can reduce the temperature in greenhouse in range of $7.05^{\circ} \mathrm{C}(18.44 \%)$ and the efficiency of fogging system is quite high (value is $57.36 \%$ ). The important factor that influents on the air temperature in greenhouse is solar power. If we need to control the atmosphere in greenhouse by fogging system than the reduction of solar power is the most important controlling factor.
\end{abstract}

\section{Introduction}

At present, the use of greenhouses is becoming increasingly popular because it is the safest way of vegetable and fruit production, enabling the control of pathogen contamination and the effective destruction of pests. The weather conditions in the greenhouse are directly influenced by solar radiation, atmospheric temperature and relative humidity [1]. During the day, the heat from solar power causes the greenhouse effect in the greenhouse which can affect the growth of many plants, resulting in low productivity or not being cultivated [2].Many researchers have tried to study and reduce the effects of these conditions. The common method is shading the sun light by covered the greenhouse roof with shading net and fogging water in greenhouse to reduce the inside air temperature. This method can result in a lower air temperature with high relative humidity that is suitable for plant growth [1].

* Corresponding author: khachonsak.simek@gmail.com 
Fogging is spraying high pressure water through nozzles to produce a mist with droplet diameter of 2-60 micrometers, increasing the air-water contact surface [3]. The fog is sprayed over the planting area to allow the fog to fall freely and come to contact with air in the greenhouse [4]. After fogging, ventilation of the greenhouse is necessary to allow new air to replace the moist air. For maximum efficiency of the fogging system, it must take no more than 1 minute for ventilating 1 air change [5]. The purpose of this article is to present the numerical technique for analyzing temperature in a fogging greenhouse with shading net covered on its roof. This technique can be used to evaluate the effect of solar power on air temperature in the greenhouse and the fogging greenhouse efficiency.

\section{Materials and methods}

\subsection{The testing of greenhouse}

The greenhouse was 4 meters wide, 8 meters long and 3 meters high, and made from galvanized steel pipes as a structure and covered with polyethylene sheets. Two 14-inch electric ventilation fans (ventilators) were installed on the greenhouse font wall. Inside the greenhouse, 18 fogging nozzles (foggers) operated with a 12-bar water pump (total mass flow rate $7.73 \times 10^{-3} \mathrm{~kg} / \mathrm{S}$ ) were installed overhead and two 10 -inch electric circulating fans were equipped on the wall. Three DHT22 sensors (ASAIR model AM2302) $\left( \pm 2 \%\right.$ of RH and $\pm 0.5^{\circ}$ $\mathrm{C}$ of air temperature) were installed to measure dry-bulb temperature and relative humidity of the air inside the greenhouse. Data collection was controlled by an Arduino board model MEGA 2560. All equipment installation is shown in Figure 1.

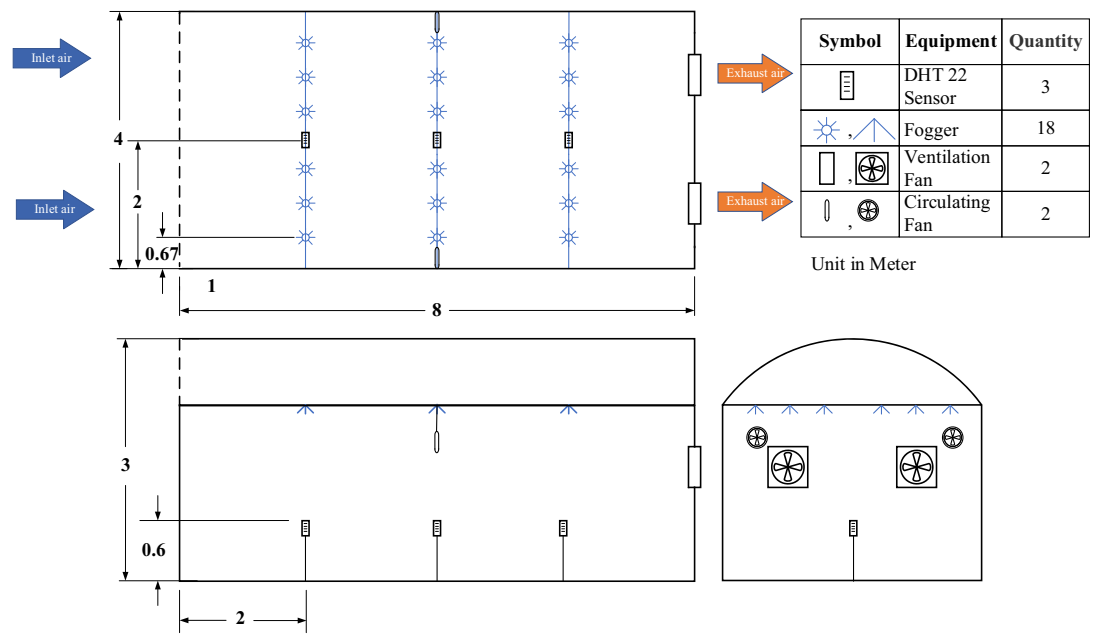

Fig. 1. Position of all equipment and sensors in greenhouse.

\subsection{Air properties}

Humidity ratio is the ratio of mass of vapor in air and mass of dry air. It can calculate from Equation 1 [6]: 


$$
x=\frac{m_{w}}{m_{a}}
$$

where $x$ is humidity ratio, $m_{w}$ is mass of vapor in air $(\mathrm{kg})$ and $m_{a}$ is mass of dry air $(\mathrm{kg})$. In addition, humidity ratio can be calculated from the relationship between partial pressure of water vapor in moist air and atmospheric pressure of moist air as in the Equations 2 and 3 [6]:

$$
\begin{aligned}
x & =0.62198 \frac{P_{w}}{P-P_{w}} \\
P & =101.325\left(1-2.25577 \times 10^{-5} Z\right)^{5.2559}
\end{aligned}
$$

where $P_{w}$ is partial pressure of water vapor in moist air, $P$ is atmospheric pressure of moist air $(\mathrm{Pa})$ and $Z$ is altitude $(\mathrm{m})$.

Relative humidity is the relationship between saturation pressure and partial pressure of water vapor can be calculated by Equation 4 [6]:

$$
\phi=\frac{P_{w}}{P_{w s}}
$$

where $\phi$ is relative humidity and $P_{w s}$ is saturation pressure (Pa). The saturation pressure over liquid water for temperature range of 0 to $200^{\circ} \mathrm{C}$ is given by Equation 5 [6]:

$$
\ln P_{w s}=\frac{C_{1}}{T_{d b}}+C_{2}+C_{3} T_{d b}+C_{4} T_{d b}^{2}+C_{5} T_{d b}^{3}+C_{6} \ln T_{d b}
$$

where $T_{d b}$ is air's dry-bulb temperature in the kelvin unit and $C$ are constants with the following values, $C_{l}=-5.800221 \times 10^{3}, C_{2}=1.391499, C_{3}=-4.864024 \times 10^{-2}, C_{4}=4.176477 \times 10^{-5}, C_{5}$ $=1.445209 \times 10^{-8}$ and $C_{6}=6.545967$.

\subsection{Mass and energy balance in greenhouse}
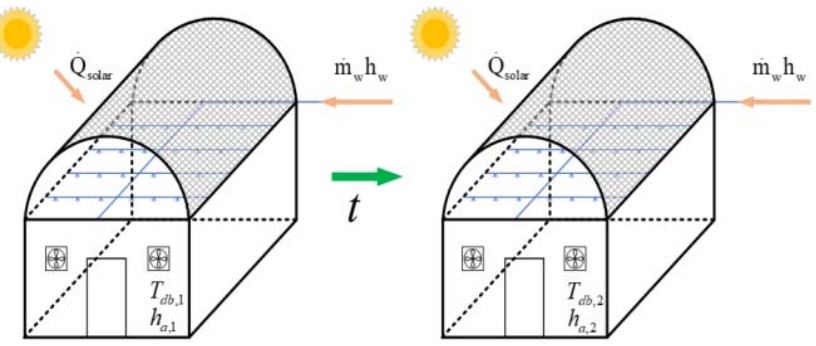

Fig. 2. Changing of air properties after exposure solar energy. 
The operation of fogging system begins when dry-bulb temperature $\left(T_{d b, 1}\right)$ and enthalpy $\left(h_{a, 1}\right)$ of air inside the greenhouse is heated by the solar power and the air receives the mass of water that has been spray from foggers for a period of $t$ second. After that, $T_{d b, 1}$ and $h_{a, 1}$ changes to $T_{d b, 2}$ and $h_{a, 2}$. The entropy of the air in the final state can be analyzed from Equation 6 :

$$
\dot{Q}_{\text {solar }}+\dot{m}_{w} h_{w}=\frac{m_{a}\left(h_{a, 2}-h_{a, 1}\right)}{t}
$$

where $\dot{Q}_{\text {solar }}$ is heat generation rate due to solar power (Watt). In this research, the solar power was measured by Solar Power Meter brand TENMARS model TM-206 $\left( \pm 0.38 \mathrm{~W} / \mathrm{m}^{2}\right)$, is a spraying time of the fogging system (S). When the air temperature is influenced by only fogging process, the term is neglected from the empirical equation. The entropy of the air in the final state for this case can be analyzed from Equation 7 :

$$
\dot{m}_{w} h_{w}=\frac{m_{a}\left(h_{a, 2}-h_{a, 1}\right)}{t}
$$

Once the value of $h_{a, 2}$. is known from Equations 6 and 7, $T_{d b, 2}$ can calculate from Equation 8 [6]:

$$
T_{d b, 2}=\frac{h_{a, 2}-2501 x_{2}}{1.006+1.805 x_{2}}
$$

\subsection{Efficiency of fogging system}

[2] Proposed a method for determining the efficiency of fogging system greenhouse via a relationship of air temperature before and after fogging process as in Equation 9:

$$
\eta_{i c}=\frac{T_{d b, 1}-T_{d b, 2}}{T_{d b, 1}-T_{w b, 2}}
$$

where $\eta_{i c}$ is efficiency of fogging system greenhouse and $T_{w b, 2}$ is wet-bulb temperature of the air in the after fogging.

\subsection{Experiment}

The greenhouse in this experiment was covered with a $50 \%$ sun shading net on the roof. Drybulb temperature and relative humidity of the air inside the greenhouse and surrounding were collected. Solar power was collected both inside the greenhouse and surrounding every 30 minutes. Testing was divided to 2 cases. In Case I, all of the parameters were measured between 9.00 a.m. to 5.00 p.m. (Thailand's time zone) without operating the fogging system and ventilation. In Case II, all of the parameters were measured with the fogging system turned on controlling the relative humidity below $80 \%$ all day. The data were analyzed with 
empirical equations to determine the dry-bulb temperature of greenhouse and efficiency of fogging system with and without solar power. The experiments were conducted at Suranaree University of Technology, Nakhon Ratchasima, Thailand, with locations, latitude $14^{\circ} 53^{\prime} 32.5^{\prime \prime} \mathrm{N}$, longitude $102^{\circ} 00^{\prime} 18.1^{\prime \prime}$ between November 17-21, 2019.

\subsection{Empirical equation of dry-bulb temperature}

Dry-bulb temperature analysis in the final state (after fogging) start by calculating the saturation pressure $\left(\mathrm{P}_{\mathrm{w}}\right)$ after that, calculates the partial pressure of water vapor in moist air $\left(\mathrm{P}_{\mathrm{ws}}\right)$ and enthalpy in the first state. Then considering that mass of dry air inside the greenhouse nothing changes. The changed part will have only the mass of water vapor in the air, therefore, ma, $1=$ ma, 2 ma. It will be able to calculate the humidity ratio of the air in the final state of the greenhouse and also leads to find the entropy from the energy balance in Figure 2 which is in the form of Equation 6. In the case calculate without solar power in the empirical equation, Equation 7 will be considered instead of Equation 6 .

\section{Results and discussion}

\subsection{Temperature of greenhouse without fogging system and ventilation}

From Figure 3, the dry-bulb temperature of air inside the greenhouse (TDB) increased with the highest value of $50.13^{\circ} \mathrm{C}$ while the relative humidity decreased. The increase in air temperature by accumulative solar energy in greenhouse caused the air to expand and raised the ability to hold more moisture. This effect caused the relative humidity $(\mathrm{RH})$ in greenhouse to decrease and the solar power during the day shown in Figure 4.

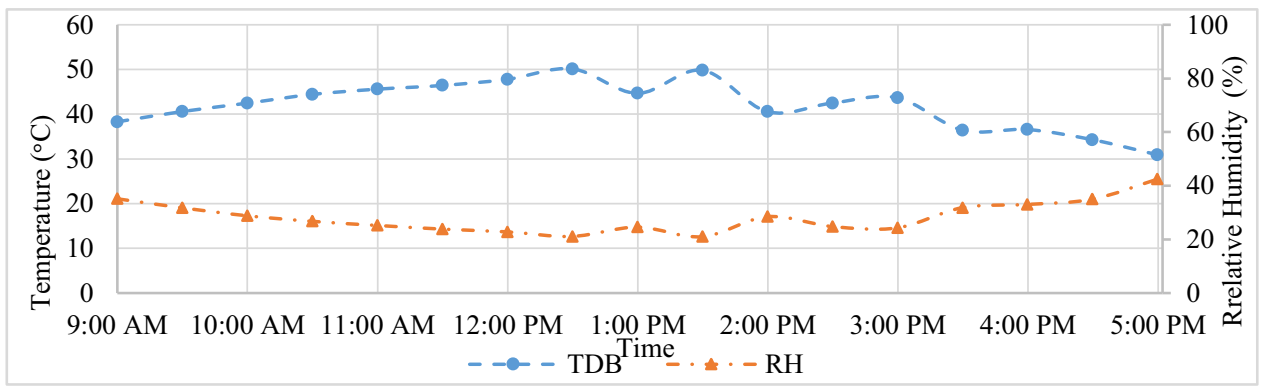

Fig. 3. Dry-bulb temperature (TDB) and relative humidity (RH) of greenhouse without fogging system and ventilation. 


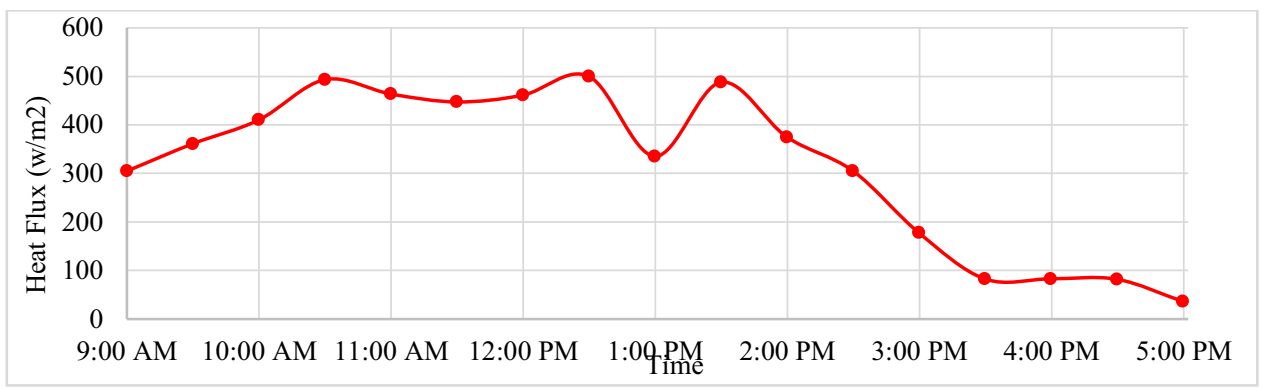

Fig. 4. Solar power (heat flux, $\mathrm{W} / \mathrm{m}^{2}$ ) under the greenhouse roof without fogging system and ventilation.

From Figure 4, heat from the transmittance of solar power into the greenhouse tended to increase until 1.30 p.m. After that, it began to decrease. The temperature of the air in the greenhouse will be vary directly to the solar power inside the house. At $1.00 \mathrm{p} . \mathrm{m}$. during the experiment, the clouds overlay the sun. Resulting the solar power into greenhouse being reduced, which is in accordance with Figure 3. At the same time the dry-bulb temperature of the air in the greenhouse will decrease for a period and the relative humidity of the air will increase during that time.

\subsection{Temperature of ventilating fogging greenhouse}

From Figure 5, TDB of the air in the greenhouse during which the relative humidity was controlled below $80 \%$ was lower than TDB from the past topic (Temperature of greenhouse without fogging system and ventilation) because of the heat of air loses to the fog. However, the heat from the solar power transmit through the greenhouse roof was quite high (Figure 6), causing higher TDB and lower RH in the greenhouse. It can be said that the resulting fogging could not alleviate the heat from the solar power.

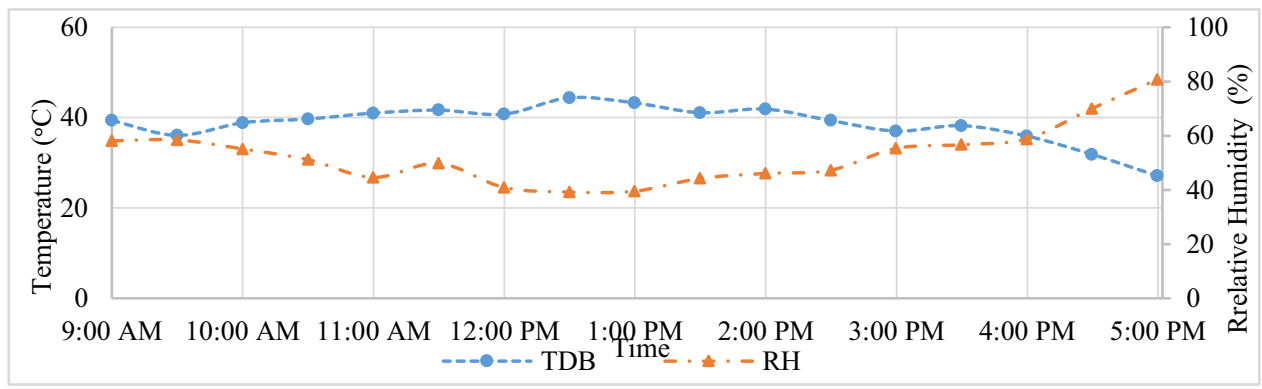

Fig. 5. Dry-bulb temperature (TDB) and relative humidity $(\mathrm{RH})$ in ventilating fogging greenhouse. 


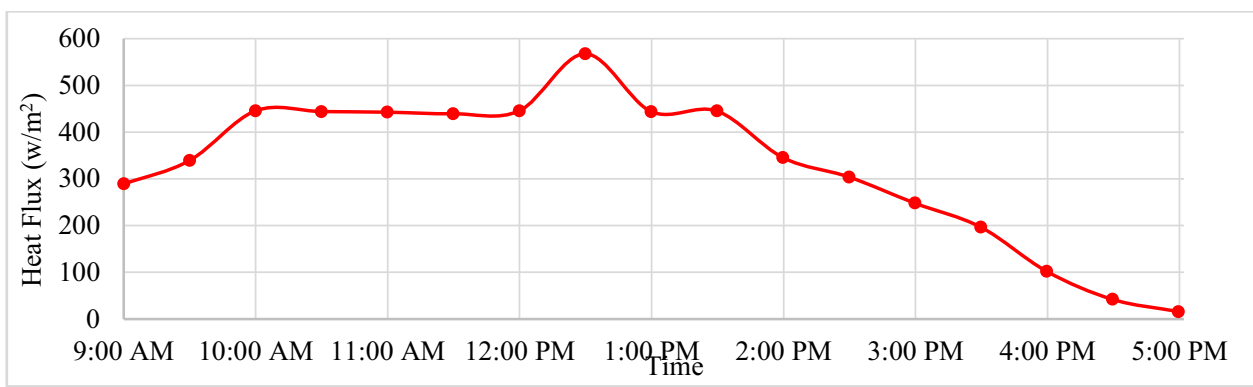

Fig. 6. Solar power (heat flux, $\mathrm{W} / \mathrm{m}^{2}$ ) under the greenhouse roof with fogging system and ventilation.

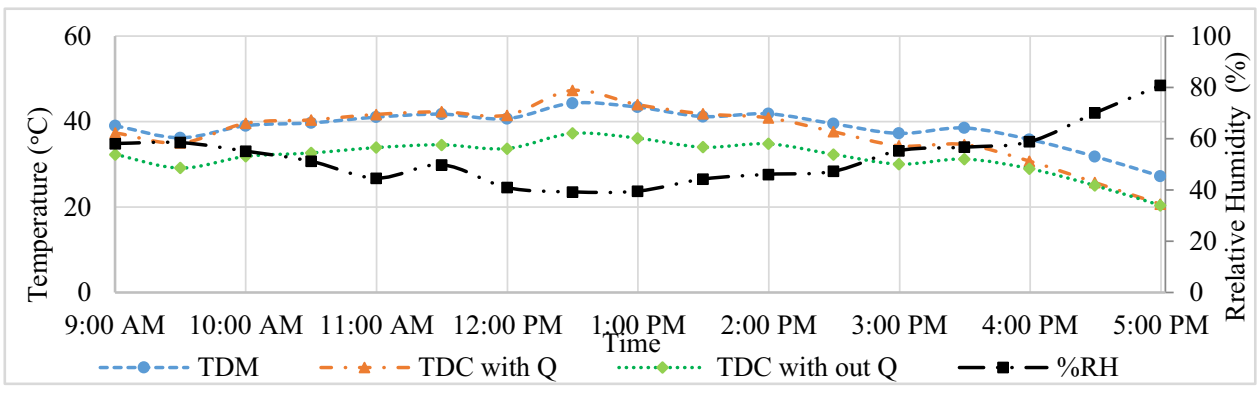

Fig. 7. Dry-bulb temperature (TDB) from empirical equation.

Figure 7 shows the TDB of the air in the greenhouse that controlled relative humidity at $80 \%$ compared with the dry-bulb temperature of the air by calculation included the solar power (TDC with Q) and neglected the solar power (TDC without Q) in empirical equations. Found that the TDC with Q was closed to the measured temperature (TDM). with an average discrepancy of $6.33 \%$. The highest TDC $\left(47.27^{\circ} \mathrm{C}\right)$ with Q occurred at the same time of TDM. The shape of TDC without Q - time curve and TDM are similar and they are related to the intensity of the solar power entering the greenhouse. The average solar power in the greenhouse is $326.84 \mathrm{~W} / \mathrm{m}^{2}$ throughout the day. The solar power is the main influence according to Equation 6 that causes TDM to rise. The numerical analysis results of neglecting solar power found that the fogging technique in greenhouse can reduce the dry-bulb temperature in the house with the highly efficiency. The temperature can be reduced throughout the experimental range about $7.05^{\circ} \mathrm{C}$ or equal to $18.44 \%$. The TDB is related to the amount of water added to the system. When the air receives more moisture, it will lose heat in form of latent heat and causing the air temperature decrease. 


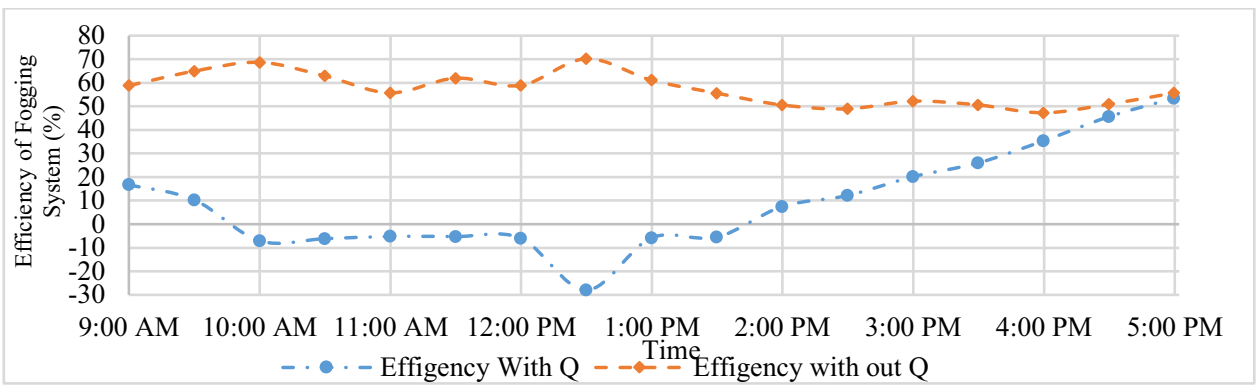

Fig. 8. Efficiency of fogging system.

Figure 8 is a comparison of the efficiency of the fogging system between calculated with and without solar power in empirical equations. It was found that the efficiency of the greenhouse after fogging in case of solar power (Efficiency with Q) was quite low. For certain periods, the efficiency of fogging was negative which means the latent heat that the air loses to the fog was less than the heat that the air received from the solar power. This behavior resulted in the TDB of the air after fogging during that time higher than TDB before fogging. In case of neglected solar power (Efficiency without Q), the efficiency of fogging system is quite high at the average value $57.36 \%$ because of the air in greenhouse does not receive more heat from solar power. Considering the results, the important factor that influents on the TDB in the greenhouse is solar power. It causes the greenhouse effect by the heat from solar power. If we need to control the atmosphere in greenhouse by fogging system than the reduction of solar power is the most important factor. However, the important thing to cultivate with greenhouses is sunlight. The selected method to control solar energy must not reduce the intensity of sun light that plants need as well. The method that may be applied is to absorb some heat energy from the roof without losing light intensity, such as using water as a coolant to reduce the roof temperature.

\section{Conclusions}

In this research the study is divided into 2 cases. Case I study of air's dry-bulb temperature and relative humidity inside the greenhouse without using the fogging system and no ventilation. Case II study air's dry-bulb temperature and relative humidity inside the greenhouse with a fogging system that was controlled the relative humidity inside not much more than $80 \%$. The results show the air temperature in case $\mathrm{I}$ is highest at $50.13^{\circ} \mathrm{C}$ and the air temperature in case II are lower than case I in all day of study. Although there is a fogging system in case II, but the heat from solar can still pass through the greenhouse all times and affected on the error of numerical studying result at $6.33 \%$ when compare to the experiment values. The neglectable of solar heat in calculation affected on the predicted temperature in greenhouse and had $18.44 \%$ of error. In term of fogging efficiency, if the solar heat was included in the calculation in some period time the efficiency are minus values because the values of inlet of solar heat is higher than the loss of latent heat in moist air. In case of negligible solar heat, the greenhouse efficiency is highest at $57.36 \%$ which can be said that the important factor that makes the temperature inside the green house higher is the heat from the solar. If we want to reduce the air temperature of the green house and increase the greenhouse efficiency, it is necessary to find a way to absorb some energy from the solar. 
However, it must not be affected by the amount of light that plants need to get enough to grow as well

The author would like to thank the School of Agricultural Engineering, Institute of Engineering, Suranaree University of Technology and for support this research.

\section{References}

1. C. Saowarat, K. Treeamnuk, T. Treeamnuk, Mathematical Model For Exact Solution Method of Fogging Process Control in Climate Greenhouse System in Proceedings of THE IRES 87th INTERNATIONAL CONFERENCE, 6-7 November 2017, Tokyo, Japan (2018)

2. A.M. Abdel-Ghany, T. Kozai, Biosystems Engineering, 94(1), 97-109(2006)

3. A. Shklyar, M. Barak, Acta Horticulturae, 534, 327-334(2000)

4. J.I. Montero, A.C. Biel, A. Franquet, Acta Horticulture, 281, 199-209(1990)

5. J. Worley, GREENHOUSES Heating, Cooling and Ventilation, Cooperative Extension (University of Georgia College of Agricultural and Environmental Sciences, 2009)

6. ASHRAE, ASHRAE Handbook Fundamentals (American Society of Heating, Refrigerating and Air-Conditioning Engineers, 2009) 